\title{
Virtual Reality as a Friend of the Elderly: A Mini-Review
}

\author{
Seyyed Mohammad Tabatabaei ${ }^{1,2,3 *}$ and Ali Talaei ${ }^{4}$ \\ ${ }^{1}$ Medical Informatics Department, School of Medicine, Mashhad University of Medical Sciences, Mashhad, Iran \\ ${ }^{2}$ Psychiatry and Behavioral Sciences Research Center, Mashhad University of Medical Sciences, Mashhad, Iran \\ ${ }^{3}$ Imam Reza Hospital Clinical Research Unit, Mashhad University of Medical Sciences, Mashhad, Iran \\ ${ }^{4}$ Division of Neurocognitive Sciences, Psychiatry and Behavioral Sciences Research Center, Mashhad University of Medical \\ Sciences,Mashhad, Iran
}

*Corresponding author: Seyyed Mohammad Tabatabaei, Ibn-e-Sina Street, Imam Reza Hospital, Department of Central Library, Clinical Research Unit, Mashhad, Iran

\begin{tabular}{|c|c|}
\hline ARTICLE INFO & ABSTRACT \\
\hline 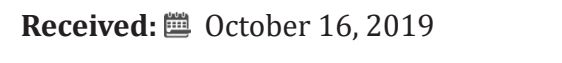 & With the increasing population of the elderly, the use of new solutions and \\
\hline Published: 慧 October 22, 2019 & $\begin{array}{l}\text { technologies to assist their rehabilitation in physical and mental disorders seems vital. } \\
\text { One of the new technologies that has been successfully applied in helping the elderly is }\end{array}$ \\
\hline $\begin{array}{l}\text { itation: Seyyed Mohammad Tabatabaei } \\
\text { Ali Talaei, Virtual Reality as a Friend } \\
\text { f the Elderly: A Mini-Review. Biomed } \\
\text { Sci \& Tech Res 22(2)-2019. BJSTR. }\end{array}$ & $\begin{array}{l}\text { Virtual Reality (VR). Considering real-world problems and limitations for old people, this } \\
\text { technology helps them to cope with their disorders and to control or treat them as much } \\
\text { as possible. Also, it may help them to perform a variety of motivational activities without } \\
\text { the help of others. This work presents an overview of the recent advances in the research } \\
\text { on using VR for helping the elderlies. }\end{array}$ \\
\hline
\end{tabular}

Keywords: Virtual Reality; Elderly; Cognitive Disorders; Balance Rehabilitation; Leisure Activities

\section{Introduction}

As life expectancy grows more, the number of elderly people who need care and assistance due to physical or psychological disabilities is rapidly increasing [1]. According to WHO reports, nowadays, $12.5 \%$ of the world's population is aged over 60 and it is predicted that it will grow to $22 \%$ by 2050 [2]. Under such circumstances, physical activity and self-care ability would be decreased which may lead to numerous social consequences such as increased family burden, decreased quality of life, increased health care needs, increased length of stay, increased costs, etc [1] So, it seems vital using new technologies as a solution to overcome these problems. One of these advanced technologies, which has recently attracted much attention in many areas such as medicine, is Virtual Reality (VR). VR is a 3-Dimentional world which is created by computers so that one can move and interact in it as if they were already there [3-8]. The elderly has also not benefited from this technology, as researchers have used it for a variety of purposes, such as evaluating the rehabilitation and treatment of memory disorders, reducing balance disorders, education, entertainment, traveling and even pain reduction [9-13]. The results of these studies showed good effects on improving mental and social status in older people. Using a virtual environment, the technology tries to alter the brain's activity and inference process and somehow deceives the brain to achieve its intended purpose. It is necessary for health professionals to recognize the influence, benefits, advantages and disadvantages of using VR in the elderly to be able to use it in the best way in clinical practice. Thus, the present study aimed to make a mini review on the application of virtual reality in the elderlies.

\section{Review of Recent Research Works}

One of the applications of VR in the elderly is to assist in the evaluation and rehabilitation of cognitive disorders, especially memory disorder, which can cause many problems for the elderly. Using advanced 3D graphics techniques, this technology provides a semi-real environment. This unreality makes one able to deal with his own disorders and work on appropriate exercises to strengthen his abilities and resolve those disorders by being in such environment which is free from the stress of being physically presented in the real environment and facing others. For example, in the field of cognitive disorder rehabilitation in the elderly, VR has been applied in different areas such as orientation and navigating 
$[14,15]$, recognizing faces [16], cognitive functioning [15-17], and also other daily activities $[18,19]$ and the results suggest that it is useful for them.

VR can also be used in balance rehabilitation in the elderly in order to help them to prevent falls which is a common problem among them since nearly $30 \%$ of them fall at least one time in a year [20]. This technology tries to discover the causes of the falls by simulating the various conditions which causes the elderly to, as well as performing multiple tests in a secure and virtual environment. Then, by using different virtual situation and performing a variety of exercises, it tries to overcome the identified causes and to improve their ability to balance in the real world [21-23].

In addition to the above, one of the most important applications of VR is to improve the quality of life in the elderly through sport, exercises and leisure activities in a safe and virtual environment [24], since they deal with some physical and mental disabilities, they have problems with their social relationships which may lead to loneliness [25]. While leisure activities are crucial to maintaining good health at an early age, VR as an alternative solution can help older people do leisure activities indoors without worrying about outside constraints or weather conditions. In fact, beside these, by using VR, they will be able to travel to different places in the world while enjoying the comfort of their homes and thus combine physical activity with tourism-recreation [26-29].

\section{Discussion}

Although some researchers believe that more studies about the VR is needed to fully understand how it works and how it affects the brain, but many studies have shown that it is useful and has had positive effects in the treatment and rehabilitation of various disorders. In fact, VR is not an alternative for direct social interaction among the elderlies, but it rather provides the opportunity to interact with other older people in a virtual environment. It is should be notice, however, that precautionary actions such as doing so in a secure environment and conducting shorter sessions at first should be considered while using this technology. There are some obstacles against using VR such as being expensive, not widely and easily accessible, low experience, need of training in, resistance and rejection by the elderly, and also fear and negative attitude of the elderly among the virtual world and technology, which should be investigated and considered in the first place to get the best results.

\section{Conclusion}

Although at first there were many doubts about the use of VR for old people, but as noted in practical examples, numerous studies have suggested its usefulness in quality improvement of life of the elderlies. These kinds of solution may strengthen the ability to communicate, social role and community belonging in older people. Since virtual reality can be adapted to different needs and conditions due to its high flexibility, it is therefore a viable option to meet the needs of the elderly and soon it will be recognized as the best friend of the elderly in the near future.

\section{References}

1. Seelye A, Schmitter-Edgecombe M, Das B, Cook D (2012) Application of cognitive rehabilitation theory to the development of smart prompting technologies. IEEE Rev Biomed Eng 5: 29-44.

2. (2015) United Nations DoEaSA, Population Division. World Ageing Population.

3. Fernandez Mayoralas G, Rojo Perez F, Martinez Martin P, Prieto Flores ME, Rodriguez Blazquez C, et al. (2015) Active ageing and quality of life: Factors associated with participation in leisure activities among institutionalized older adults, with and without dementia. Aging Ment Health 19(11): 1031-1041.

4. Bauman A, Merom D, Bull FC, Buchner DM, Fiatarone Singh MA (2016) Updating the evidence for physical activity: Summative reviews of the epidemiological evidence, prevalence, and interventions to promote “active aging”. Gerontologist 56(Suppl_2): S268-S280.

5. Donath L, Rössler R, Faude $O$ (2016) Effects of virtual reality training (exergaming) compared to alternative exercise training and passive control on standing balance and functional mobility in healthy community-dwelling seniors: A meta-analytical review. Sports Med 46(9): 1293-1309.

6. Howe KB, Suharlim C, Ueda P, Howe D, Kawachi I, et al. (2016) Gotta catch'em all! Pokémon GO and physical activity among young adults: Difference in differences study. bmj 355: 16270.

7. Althoff T, White RW, Horvitz E (2016) Influence of Pokémon Go on physical activity: Study and implications. J Med Internet Res 18(12): e315.

8. Moline J (1997) Virtual reality for health care: A survey. Stud Health Technol Inform 44: 3-34.

9. Hwang J, Lee S (2017) The effect of virtual reality program on the cognitive function and balance of the people with mild cognitive impairment. J Phys Ther Sci 29: 1283-1286.

10. Saldana SJ, Marsh AP, Rejeski WJ, Haberl JK, Wu P, et al. (2017) Assessing balance through the use of a low-cost head-mounted display in older adults: A pilot study. Clin Interv Aging 12: 1363-1370.

11. García-Betances RI, Jiménez-Mixco V, Arredondo MT, Cabrera-Umpiérrez MF (2014) Using Virtual Reality for Cognitive Training of the Elderly. Am J Alzheimers Dis Other Demen 30(1): 49-54.

12. Benoit M, Guerchouche R, Petit PD, Chapoulie E, Manera V, et al. (2015) Is it possible to use highly realistic virtual reality in the elderly? A feasibility study with image-based rendering. Neuropsychiatr Dis Treat 11: 557-563.

13. Lin CX, Lee C, Lally D, Coughlin JF (2018) Impact of Virtual Reality (VR) Experience on Older Adults' Well-Being Cham: Springer International Publishing.

14. (2012) World Health Organization. Dementia: A public health priority.

15. Buss B (2009) Virtual Reality Training System for Patients with Dementia. Master Thesis.

16. Boggio PS, Valasek CA, Campanhã C, Giglio AC, Baptista NI, et al. (2011) Non-invasive brain stimulation to assess and modulate neuroplasticity in Alzheimer's disease. Neuropsychol Rehabil 21(5): 703-716.

17. Optale G, Urgesi C, Busato V, Marin S, Piron L, et al. (2010) Controlling memory impairment in elderly adults using virtual reality memory training: a randomized controlled pilot study. Neurorehabil Neural Repair 24(4): 348-357.

18. Belleville S, Clément F, Mellah S, Gilbert B, Fontaine F, et al. (2011) Training-related brain plasticity in subjects at risk of developing Alzheimer's disease. Brain 134(pt 6): 1623-1634. 
19. Imbeault F, Bouchard B, Bouzouane A (2011) Serious Games in Cognitive Training for Alzheimer's Patients. IEEE 1st Inter Conf Serious Games and Applicat for Health (SeGAH), Braga: IEEE.

20. Santos SS, da Silva ME, de Pinho LB, Gautério DP, Pelzer MT, et al. (2012) Risk of falls in the elderly: An integrative review based on the north American nursing diagnosis association. Rev esc enferm usp 46(5): 1227-1236

21. Duque G, Boersma D, Loza-Diaz G, Hassan S, Suarez H, et al. (2013) Effects of balance training using a virtual-reality system in older fallers. Clin interv aging 8: 257-263.

22. Laufer Y, Dar G, Kodesh E (2014) Does a wii-based exercise program enhance balance control of independently functioning older adults? A systematic review. Clin interv aging 23(9): 1803-1813.

23. Singh DKA; Rajaratnam BS, Palaniswamy V, Raman VP, Bong PS, et al. (2013) Effects of balance-focused interactive games compared to therapeutic balance classes for older women. Climacteric 16(1): 141146.

ISSN: 2574-1241

DOI: 10.26717/BJSTR.2019.22.003723

SM Tabatabaei. Biomed J Sci \& Tech Res

(C) This work is licensed under Creative

Submission Link: https://biomedres.us/submit-manuscript.php
24. Aylaz R, Aktürk Ü, Erci B, Öztürk H, Aslan H (2012) Relationship between depression and loneliness in elderly and examination of influential factors. Arch Gerontol Geriatr 55(3): 548-554.

25. Kahng SK (2008) Overall successful aging: Its factorial structure and predictive factors. Asian Soc Work Policy Rev 2: 61-74.

26. Kim A, Darakjian N, Finley JM (2017) Walking in fully immersive virtual environments: An evaluation of potential adverse effects in older adults and individuals with Parkinson's disease. J Neuroeng Rehabil 14(1): 16.

27. Jeng, MY, Pai FY, Yeh TM (2017) The Virtual Reality Leisure Activities Experience on Elderly People. App Resea Qual Life 12: 49.

28. Hsieh MC, Lin YH (2017) VR and AR Applications in Medical Practice and Education. Hu Li Za Zhi 64(6): 12-18.

29. Lin CS, Jeng MY, Yeh TM (2018) The Elderly Perceived Meanings and Values of Virtual Reality Leisure Activities: A Means-End Chain Approach. Int J Environ Res Public Health 15(4): 663.

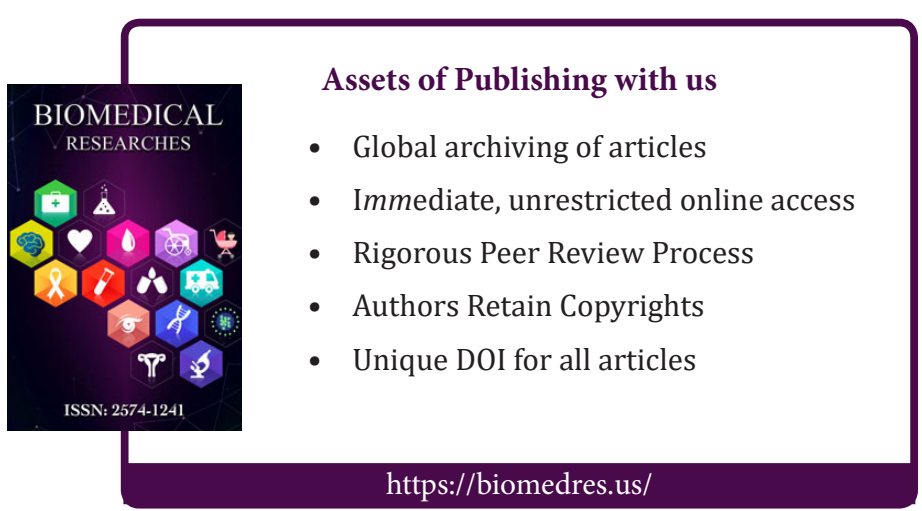

